\title{
Blood Corticotrophin Decreased, CTCAE
}

National Cancer Institute

\section{Source}

National Cancer Institute. Blood Corticotrophin Decreased, CTCAE. NCI Thesaurus. Code C143326.

A finding based on laboratory test results that indicate an decrease in levels of corticotrophin in a blood specimen. 